\title{
Evaluation of Suitable Scale Factor for Irregular Building Structure
}

\author{
Revannath J. Salunke, Vidyarani S. kshirsagar, Avinash B. Kokare, Shrikrishna A. Gosavi, Nitin
}

A. Shinde

\begin{abstract}
Irregularity are not avoidable in construction of a building. Building structure are almost irregular, as ideal perfect regularity very hardly occurs now days. As far as building structures are concerned, for practical use, Indian seismic code splits irregularity in structure which are plan irregularity and vertical irregularity. Plan irregularity is due to re-entrant corner with some torsion in the building structure. This investigation, aims to study the linear static and linear dynamic analysis (response spectrum analysis) with ETABS 2016. In the structure, which scale factor is dominant either base shear scale factor or torsion scale factor? Ten different shape of model is taken with re-entrant ratio is greater than $15 \%$ of that building structure. Mode dominance factor is calculated with the help of 1 st mode of all the building. While calculating the base shear of the response spectrum analysis, matching is done for both base shear scale factor and torsion scale factor. Behaviors of all the $\mathbf{1 0}$ structures are observed and comparison between both the scale factor is done. Investigation is done with the different shape of the building structure and appropriate results are found.
\end{abstract}

Index Terms - Building structure, Indian seismic code.

\section{INTRODUCTION}

A disruptive disturbance, that causes shaking of the surface of the earth due to underground movement along a fault plane or from volcanic activity is called earthquake. Earthquake, a natural calamity has taken toll of millions of lives through the ages. The earthquake ranks as one of the most destructive events recorded so far in India in terms of death toll \& damage to infrastructure. The major cities affected by the earthquake in the recent times are Bhuj, Gandhi Dham, and Rajkot etc. Every earthquake leaves a trail of misery because of the loss of life and destruction. Recently some shocks were experienced in the regions of Nanded, Yavatmal and Washim districts. In this study with irregular structure calculation of mode dominance factor with scale factor of base shear and torsion is being performed. Torsion subjected to the twisting moment of the structure is depended on the many factors such as configuration of building, irregular shape of the building, orientation of the column, ductility and stiffness of the building. Torsion can occur

Revannath salunke, PG student, Department of Civil Engineering, Solapur University, SVERI's College of Engineering, Pandharpur

Vidyarani kshirsagar, Associate professor Department of Civil Engineering, Solapur University, SVERI's College of Engineering, Pandharpur.

Avinash Kokare, Assistant professor, Department of Civil Engineering, Solapur University, SVERI's College of Engineering, Pandharpur.

Shrikrishna Gosavi, Assistant professor, Department of Civil Engineering, Solapur University, SVERI's College of Engineering, Pandharpur. different manner like orientation of the building, position of the column. Base shear subjected to the maximum lateral force occurred in the base of the building.

\section{A)Plan irregularity}

The different types of plan irregularities are follows-

\section{Torsional irregularity}

The building is said to be torsion irregular when, the maximum horizontal displacement of any floor in the dedicated direction of lateral force at one end of the floor is more than 1.5 times its minimum horizontal displacement at the far end of the same floor in the dedicated direction.

\section{Re-entrant corner}

Structures is said to have re-entrant corner in dedicated plan direction, when its structural configuration in plan has an orthogonal projection of size greater than $1.5 \%$ of its overall plan dimension in that direction.

\section{Floor slab having excessive cut-outs or openings}

In this irregularity a structure is said to be have discontinuity in there in plan stiffness, when floor slab has cut-outs or opening of area more than $50 \%$ of the full area of the floor slab.

\section{B) Vertical irregularity}

Stiffness irregularity (Soft storey)

A soft storey is a storey whose lateral stiffness is less than that of the storey above.

\section{Mass irregularity}

Mass irregularity shall be considered to exist, when the seismic weight of any floor is more than 150 percent of that of the floor below.

\section{Vertical geometry irregularity}

Vertical geometry irregularity is considered when the horizontal dimension of the lateral force resisting system in any storey is more than 125 percent of the storey below.

\section{METHODOLOGY}

\section{A) Linear static analysis}

linear static analysis with the gravity load imposed on the structure has been carried out Linear static analysis has two 
main assumptions:

The structure's behaviour is linear (must obey Hooke's Law). Forces are linearly proportional to deformation. If you double the loads, the response (displacements, strains, stresses) also double. Stress is proportional to strain. When the loading is removed the material must return to its original shape. (No plastic deformation). Boundary conditions do not vary during the application of loads.

\section{B) Response spectrum analysis}

This approach permits the multiple modes of response of a building to be taken into account (in the frequency domain). This is required in many building codes for all except very simple or very complex structures. The response of a structure can be defined as a combination of many special shapes (modes) that in a vibrating string correspond to the "harmonics". Computer analysis can be used to determine these modes for a structure. For each mode, a response is read from the design spectrum, based on the modal frequency and the modal mass, and they are then combined to provide an estimate of the total response of the structure. In this we have to calculate the magnitude of forces in all directions i.e. $\mathrm{X}, \mathrm{Y}$ $\& \mathrm{Z}$ and then see the effects on the building. Combination methods include the following:

- absolute - peak values are added together

- Square Root of the Sum of the Squares (SRSS)

- Complete Quadratic Combination (CQC) - a method that is an improvement on SRSS for closely spaced modes.

The result of a response spectrum analysis using the response spectrum from a ground motion is typically different from that which would be calculated directly from a linear dynamic analysis using that ground motion directly, since phase information is lost in the process of generating the response spectrum.

\section{C) Software used for Analysis (ETABS 2016)}

ETABS is a sophisticated, yet easy to use, special purpose analysis and design program developed specifically for building systems. ETABS 2016 features an intuitive and powerful graphical interface coupled with unmatched modeling, analytical, design, and detailing procedures, all integrated using a common database. Although quick and easy for simple structures, ETABS can also handle the largest and most complex building models, including a wide range of nonlinear behaviors necessary for performance-based design, making it the tool of choice for structural engineers in the building industry. Seismic parameter is shown in table. 1 .

Table.1. Seismic parameter

\begin{tabular}{|c|l|l|}
\hline Sr. No. & \multicolumn{1}{|c|}{ Parameter } & \multicolumn{1}{c|}{ Value } \\
\hline 1 & Response reduction factor & 5 \\
\hline 2 & Importance factor & 1.5 \\
\hline 3 & Soil Condition & Medium (II) \\
\hline 4 & Type of frame & SMRF \\
\hline 5 & Zone & IV \\
\hline
\end{tabular}

Table. 2. Thickness of shear wall

\begin{tabular}{|c|l|c|}
\hline Model & \multicolumn{1}{|c|}{ Name of the models } & $\begin{array}{c}\text { Shear wall } \\
(\mathbf{m m})\end{array}$ \\
\hline 1 & $\begin{array}{l}\text { Shape + Model with Shear walls at } \\
\text { corner }\end{array}$ & 160 \\
\hline 2 & $\begin{array}{l}\text { Diagonal shape with shear wall at } \\
\text { corner }\end{array}$ & 160 \\
\hline 3 & H shape with the shear wall & 160 \\
\hline
\end{tabular}

\section{D) Plan of the Structure}

\section{Model-1}

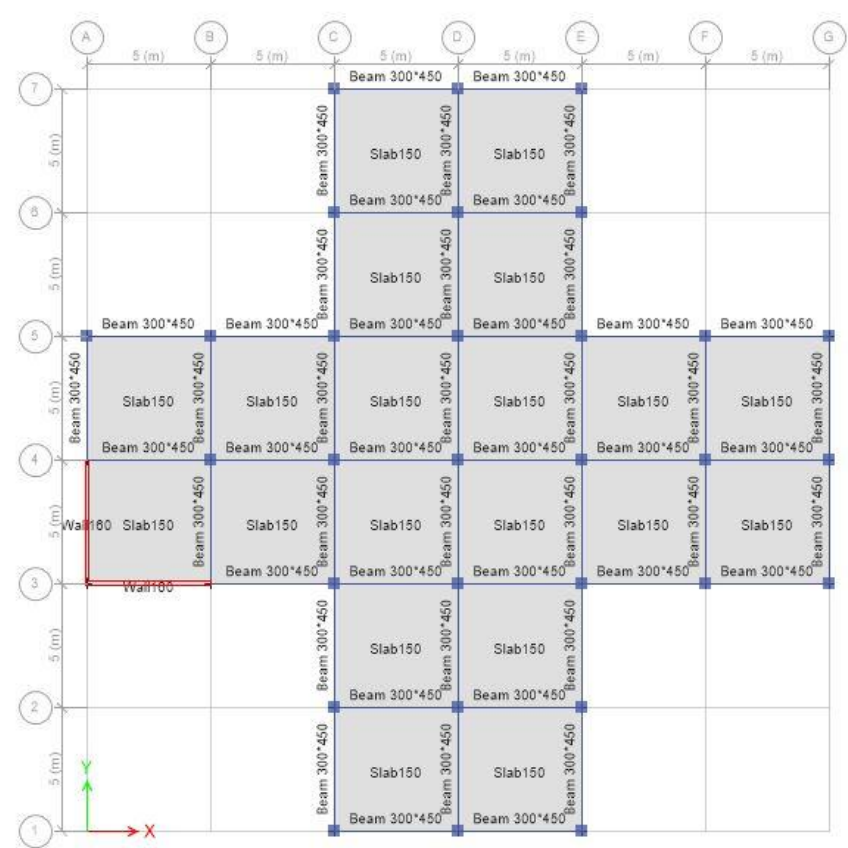

Fig.1. + Shape building with shear wall

\section{Model-2}

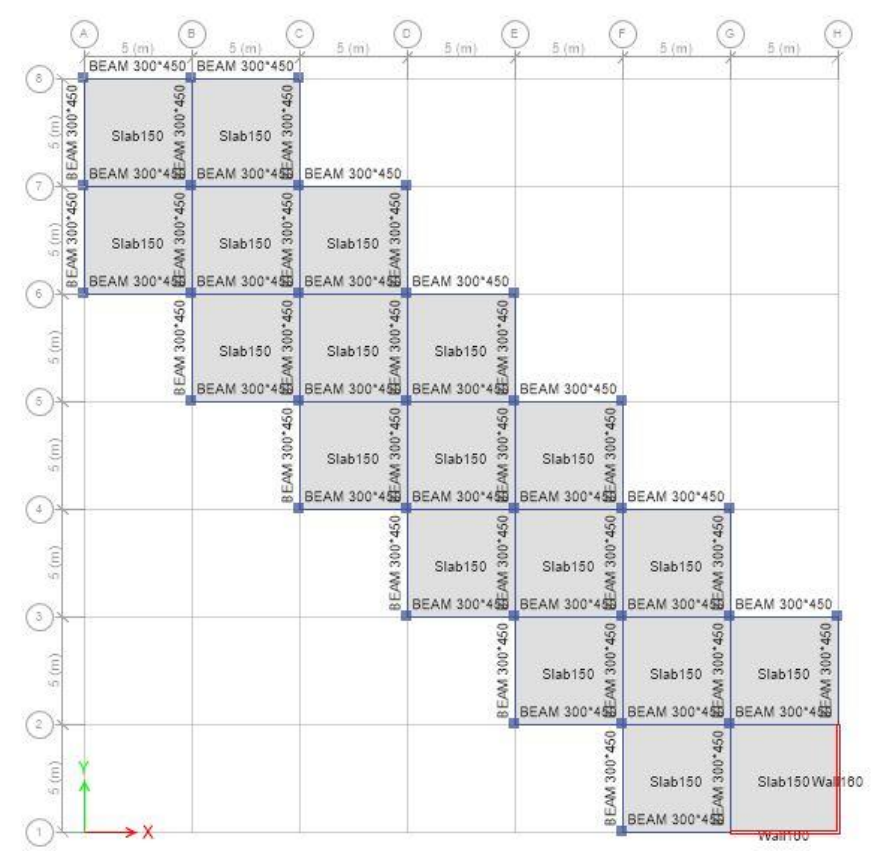
Model-3

Fig.2. Diagonal shape with corner shear wall 


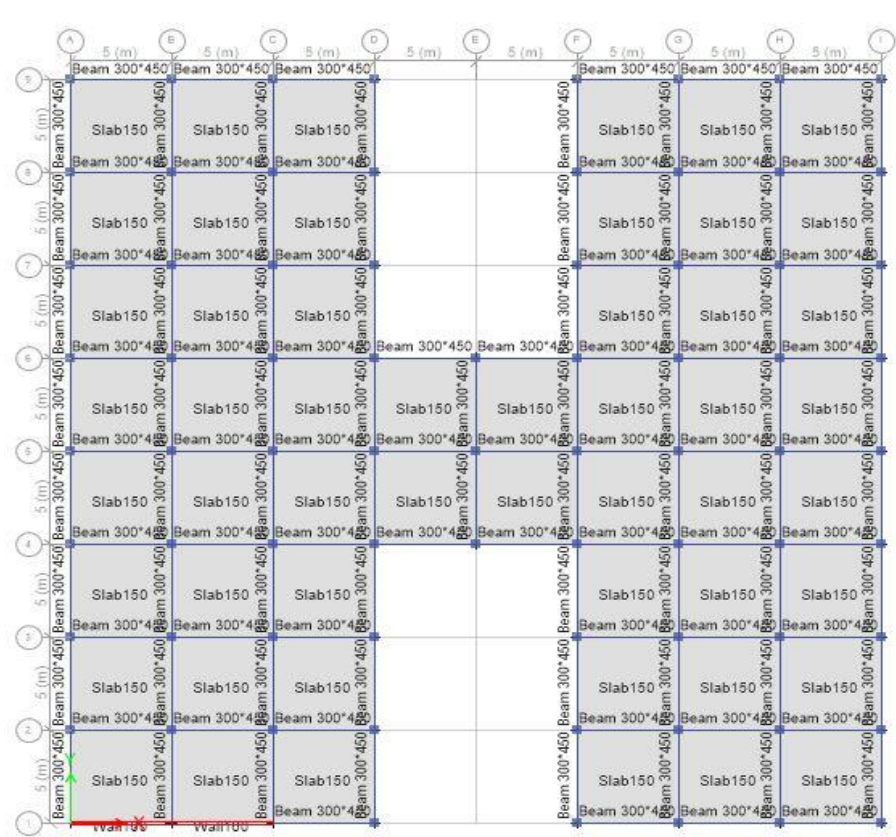

Fig.3. Shape $H$ with shear wall in $\mathrm{x}$ direction

\section{RESULTS AND OBSERVATION}

Static analysis and Dynamic analysis of 3 models were performed by using ETABS 2016 Software. The result obtaining from the analysis are as follows which are compared with all the models.

Table.3. Base reaction of linear static analysis

\begin{tabular}{|c|c|c|c|c|c|}
\hline $\begin{array}{c}\text { Model } \\
\text { No. }\end{array}$ & $\begin{array}{c}\text { Name of } \\
\text { Buildings }\end{array}$ & \multicolumn{4}{|c|}{ Base reaction } \\
\hline & & $\mathrm{FX}$ & $\mathrm{MZ}_{\mathrm{X}}$ & $\mathrm{FY}$ & $\mathrm{MZ}_{\mathrm{Y}}$ \\
\hline 1 & Shape + & 1955.07 & 41987.30 & 1661.92 & 35596.11 \\
\hline 2 & $\begin{array}{c}\text { Diagonal } \\
\text { shape }\end{array}$ & 1741.76 & 40924.09 & 1741.76 & 41315.56 \\
\hline 3 & H shape & 4015.94 & 82122.93 & 4049.82 & 82861.96 \\
\hline
\end{tabular}

Table.4. Base reaction of response spectrum analysis of $1^{\text {st }}$ scale factor

\begin{tabular}{|c|c|c|c|c|c|}
\hline $\begin{array}{c}\text { Model } \\
\text { No. }\end{array}$ & Name of buildings & \multicolumn{4}{|c|}{ Base reaction } \\
\hline & & $\mathrm{FX}$ & $\mathrm{MZ}_{\mathrm{X}}$ & $\mathrm{FY}$ & $\mathrm{MZ}_{\mathrm{Y}}$ \\
\hline 1 & Shape + & 1.41 & 23.76 & 1.16 & 31.41 \\
\hline 2 & Diagonal shape & 1 & 27.96 & 1 & 27.96 \\
\hline 3 & H shape & 2.98 & 73.98 & 3.54 & 71.27 \\
\hline
\end{tabular}

Above table.3. shows that the base reaction of equivalent static analysis of all the models, as the shape of the building changes the base reaction also change.

In table.4. shows the base reaction of response spectrum analysis after using $1 \mathrm{st}$ scale factor that is $\mathrm{SF}=\frac{\mathrm{Ig}}{(2 \mathrm{R})}$ where ' $\mathrm{I}$ ' is the importance factor, ' $\mathrm{g}$ ' acceleration due to gravity and ' $R$ ' is the response reduction factor.

$$
\begin{gathered}
\mathrm{SF}=\frac{\mathrm{Ig}}{(2 \mathrm{R})} \\
\mathrm{SF}=\frac{1.5 * 10}{2 * 5} \\
\mathrm{SF}=1.5
\end{gathered}
$$

Base reaction of the $1^{\text {st }}$ scale factor is less as compared to the static analysis computed values.

According to the IS 1893:2016 (part-1) the base shear of dynamic analysis is should not be less than the base shear of static analysis. If it's less then increased the value of scale factor of the $1^{\text {st }}$ run such that the resultant base shear matches the code specification.

Table.5. Base reaction after matching base shear scale factor

\begin{tabular}{|c|c|c|c|c|c|}
\hline $\begin{array}{c}\text { Model } \\
\text { No }\end{array}$ & Name of buildings & \multicolumn{4}{|c|}{ Base reaction } \\
\hline & & $\mathrm{FX}$ & $\mathrm{MZ}_{\mathrm{X}}$ & $\mathrm{FY}$ & $\mathrm{MZ}_{\mathrm{Y}}$ \\
\hline 1 & Shape + & 1964.61 & 32953.99 & 1672.99 & 45009.60 \\
\hline 2 & Diagonal shape & 1756.05 & 48706.80 & 1755.55 & 47358.49 \\
\hline
\end{tabular}

\begin{tabular}{|c|c|c|c|c|c|}
\hline $\begin{array}{c}\text { Model } \\
\text { No }\end{array}$ & Name of buildings & \multicolumn{4}{|c|}{ Base reaction } \\
\hline & & $\mathrm{FX}$ & $\mathrm{MZ}_{\mathrm{X}}$ & $\mathrm{FY}$ & $\mathrm{MZ}_{\mathrm{Y}}$ \\
\hline 1 & Shape + & 2503.83 & 41998.72 & 1230.67 & 35603.12 \\
\hline 2 & Diagonal shape & 1475.74 & 40932.03 & 1531.98 & 41327.46 \\
\hline 3 & H shape & 3308.45 & 82129.77 & 4121.31 & 82863.71 \\
\hline
\end{tabular}

\section{CONCLUSION}

- In X direction Model $1^{\text {st }}$ Torsion scale factor provides with greater base reaction compared to base shear scale factor.

- In Y direction Model $3^{\text {rd }}$ Torsion scale factor provides with greater base reaction compared to base shear scale factor.

- Displacement and drift of torsion scale factor is more than the base shear scale factor the torsion is more dominant in the building. Displacement and drift of both base shear scale factor and torsion scale factor are within the limits given by IS 1893:2016 (part 1).

\section{REFERENCES}

[1] "ETABS 2016 CSI Analysis Reference Manual"

[2] "ETABS 2016 Integrated Finite Elements Analysis and Design of Structures" tutorial manual.

[3] Eggert V. Valmundsson, James M. Nau (1997) "seismic response of building frames with vertical structural irregularities" Journal of Structural Engineering, Vol.123, No. I, per page. Paper No. 10825

[4] IS 1893-2002(Part-1), "Criteria for Earthquake resistant design of structures, General provisions and buildings", Bureau of Indian Standards, New Delhi.

[5] Jack P. Moehle, Luis F. Alarcon, (1986) "Seismic analysis methods for irregular Buildings" Journal of Structural Engineering, Vol. 112, No.1, Paper No. 20289. 
[6] Jack P. Moehle (1984) "seismic response of vertically irregular structures", Journal of Structural Engineering, Vol. 110, No. 9, Paper No. 19161.

[7] James M. Nau, William J. Hall (1984) "Scaling methods foe earthquake response spectra" Journal of Structural Engineering, Vol. 110, No. 7,0007-1533.

[8] Michel bruneau, and stephen, mahin, member, (1990) "normalizing inelastic seismic response of Structures having eccentricities in plan" Journal of Structural Engineering, Vol. 116, No. 12, 0012-3358. Paper No. 25359.

[9] Saudagar M. shujahuddin, pranesh B. Murnal (2017) "Effect of re-entrant corner irregularity in a structure", journal of structural engineering management, Vol.4, No 3, ISSN 2393-8773/3 pp31-37.

[10] Sharon, wood (1992) "seismic response-of $\mathrm{r} / \mathrm{c}$ frames with irregular profiles" journal of structure at engineering, vol. 118, no. 2, pp0002 0545 . 